\title{
Exploring Sufficiency Conditions for Entrepreneurial Environment and Counseling Activities on Entrepreneurial Performance
}

\author{
Shang-Yung Yen ${ }^{1}$, Ting-Hsiang Tseng ${ }^{2} \&$ Song-Ching Fan ${ }^{3}$ \\ ${ }^{1}$ Graduate Institute of Management of Technology, Feng Chia University, Taiwan \\ ${ }^{2}$ Department of International Trade, Feng Chia University, Taiwan \\ ${ }^{3}$ Ph.D. Program in Business, Feng Chia University, Taiwan \\ Correspondence: Song-Ching Fan, Ph. D Program in Business, Feng Chia University, 100, Wen-Hwa. Rd., \\ Taichung City 40724, Taiwan ROC. E-mail: scott_fan@hotmail.com
}

Received: April 3, 2014

Accepted: April 20, 2014

Online Published: June 25, 2014

doi:10.5539/ibr.v7n7p1

URL: http://dx.doi.org/10.5539/ibr.v7n7p1

\begin{abstract}
This empirical study aims to explore sufficiency conditions for Entrepreneurial Resources and Counseling Activities on Entrepreneurial Performance. The study collected 111 questionnaires from entrepreneurs in Taiwan and applied fuzzy set qualitative comparative analysis (fs/QCA) to explore the sufficiency conditions for entrepreneurial environment and counseling activities on entrepreneurial performance. In a regression analysis, there was no significant finding regarding the effects of entrepreneurial counseling on entrepreneurial performance. However, the fs/QCA analysis results show there is high causal relevance of entrepreneurial environment, entrepreneurial counseling and a combination of these two on entrepreneurial performance. Specifically, when entrepreneurial environment are available, the results $(\mathrm{Y})$ of entrepreneurial performance are probably yielded. When entrepreneurial counseling is available, entrepreneurial performance can be created. Finally, when a combination of entrepreneurial environment and entrepreneurial counseling are available, entrepreneurial performance can be yielded. This study suggests that fs/QCA is a useful method to provide a calculus of compatibility and thus to contribute to an enhanced understanding of entrepreneurial environment and counseling activities on entrepreneurial performance.
\end{abstract}

Keywords: entrepreneur environment, entrepreneur counseling activities, entrepreneur performance, fuzzy set qualitative comparative analysis (fs/QCA)

\section{Introduction}

The aim is to explore sufficiency conditions for entrepreneurial environment and counseling activities on entrepreneurial performance. The establishment of new businesses can generate economic value, but can also be equipped with risks, uncertainties and a high degree of failure. The studies show that $15-20 \%$ of entrepreneurs did not utilize the entrepreneurial resources available during the establishment of their business, such as information on laws and regulations, taxation, finances and technology etc. (Lundström \& Kremel, 2011). Zhao et al. (2010) further believe that in the process of counseling and training activities, more efforts should be made to understand the personality of the entrepreneurs. Taticchi et al. (2009) holds that entrepreneurial competitiveness lies in the utilization of resources, such as strategic partners, and network technology to create value, rather than the type of industry or company. Wu (2009) believes that the unique method of allocation of entrepreneurial resources for entrepreneurs determines the development and the establishment of businesses.

In addition, due to their lack of management knowledge, the chance of failure for these entrepreneurs is increasing. Therefore, the attitude of entrepreneurs towards the resources on offer affects their entrepreneurial performance. Eileen et al. (1993) also point out that to strengthen the understanding and counseling activities, entrepreneurial experience is quite significant. Karunanithy and Jeyaraman (2013) believed that entrepreneurial counseling activities are vital necessities that can improve entrepreneurial performance and enhance entrepreneurial abilities. For example, in the early stage of the establishment of a business, entrepreneurs can do everything themselves. With an increase in business, however, and the establishment of an effective management mechanism through the entrepreneurial counseling activities, the workload can be shared and cooperation is needed to ensure that employees strive for different goals. In addition, they have to locate the reasons for any 
previous mistakes rather than repeat the same mistakes. Through appropriate counseling activities, entrepreneurs are encouraged to discover their own abilities and goals (Karunanithy \& Jeyaraman, 2013). Therefore, during the establishment of a business, related entrepreneurial counseling activities can promote the knowledge and skills of entrepreneurs to reduce any risk and uncertainties, boost their confidence, reduce the fear of business failure and promote the chances for success (Brown, Doyle, Lewis, Mallette \& Young, 2002; Sharma et al., 2012; Karunanithy \& Jeyaraman, 2013).

In summary, entrepreneurial counseling activities are of great importance and enhance the improvement of entrepreneurial results. At present, many entrepreneurial counseling activities not only promote the knowledge and skills of entrepreneurs, but also offer new opportunities for new businesses and counseling for enterprise planning, which are vital to entrepreneurs (Kevin, 1999). However, the reality is that the importance of entrepreneurial counseling activities is rarely highlighted. This study plans to explore whether a combination of entrepreneurial resources and entrepreneurial counseling are available, entrepreneurial performance can be yielded.

\section{Literature Review}

\subsection{Entrepreneurial Environment}

Entrepreneurial environment refers to combination of factors that play a role in the development of entrepreneurship (Fogel, 2001). Empirical studies of various countries show that countries that keep rules and regulations at a minimum, offer tax and other incentives, and provide training and counseling services to start-up entrepreneurs increase the likelihood of new venture development. The above implies entrepreneurial environment is defined as resources. Srivastava et al. (1998) believe that resources are defined as "market-based assets" and also defined as "the resources generated by the interaction between internal and external environment in enterprises and could create values for customers and financial values". Barney (1991) classified the enterprises resources into three types: the first type is Physical Capital Resources (PCR) consisting of the utilization of practical technologies; the second type is Human Capital Resources (HCR) and includes experience, intelligence counseling activities, relationship, and personal management insight; the final one is Organizational Capital Resources (OCR) and contains formal and informal planning, the non-formal relationship inside the company and the relationship between the company and the external environment. Grant (1991) proposed resource-based theory and believed that the profitability of companies relies on their attractiveness and competitive advantages. The basis for the competitive advantages comes from their resources.

In recent years, in the study of entrepreneurial management, resources have been developed as the key factor determining whether the company will acquire success or not (Kralj \& Markič, 2008). Entrepreneurial environment are the tangible and intangible resources that can offer the biggest assistance with laws and regulations for entrepreneurs with the minimum effort. These could assist in offering taxation reduction and various financial resources, technologies, the utilization of labor forces, and entrepreneurial counseling activities (Lichtenstein \& Brush, 2001; Dollingers, 2003). In particular, in the early stage of a new business, intangible assets, such as technology and management, etc. are much more important than tangible assets (Lichtenstein \& Brush, 2001).

\subsection{Entrepreneur Counseling Activities}

Recent researches suggest that entrepreneurship is embedded in a social context capacity (Gourova et al., 2009). For each entrepreneur, knowledge plays a key role in their business and determines the effectiveness of their entrepreneurship (Mocanu et al., 2010). Counseling activities enable entrepreneurs to learn innovative management, develop the implicit knowledge of entrepreneurship, enhance the knowledge and skills of entrepreneurs and put them into organizational practice so as to reduce the risks and uncertainties that indirectly affect business performance (Kralj \& Markič, 2008; James et al., 2012).

Entrepreneurial counseling activities refer to the capable consultants that assist at entrepreneur school and determine their entrepreneurial planning to enhance business quality and on-the-job diagnosis etc. (Liang Jinshu, 2010). The importance of entrepreneurial counseling activities is that it can assist enterprises to solve any issues in their business management. In addition, governments can understand the planned enterprise strategies through business counseling activities that promote competitive advantage (Wang, 2009). Nagesh and Murthy (2008) believed that the content of entrepreneurial counseling activities consists of the counseling activities of entrepreneurial motive and possible obstacles in entrepreneurism, the writing of entrepreneurial proposals, marketing, management and leadership etc. However, the counseling policies of entrepreneurial counseling activities are not necessarily in line with the individual needs of the entrepreneurs (Lu \& Liang, 2008). The government needs to use professional knowledge during the utilization and operation of the assets of 
entrepreneurial counseling activities, including the selection of sites, counseling activities for marketing management, technological counseling activities and on-the-job counseling activities etc. (Guo, 2003).

\section{Methodology}

In response to the previous research goal, this study focuses on the study of the influence of entrepreneurial counseling activities and entrepreneurial environment on entrepreneurial performance.

This study applied fuzzy set qualitative comparative analysis (fs/QCA) to examine proposed arguments. Unlike traditional statistics which detects patterns of relationships between variables, fs/QCA focuses on examining the configurations of cases that constitute the rows of a data matrix (Chang et al., 2013). This method provides researchers a huge opportunity to explore or re-exam some previously neglected or disproved relationship/arguments. The current study would like to use a traditional statistic method (i.e., regression) to test the relationships between variables first, and then apply fs/QCA on the same set of data to validate the proposed arguments.

\subsection{Sample and Data Collection}

Based on the over three years of entrepreneurs of the Association of Taiwanese Chain and Franchise Promotion, this study adopts those entrepreneurs on the Phoenix Ventrue plan (issued by the Council of Labor Affairs, Executive Yuan) as the test samples. 478 questionnaires were distributed on the job website between Dec 2012 to Dec 2013 of which 134 copies were returned. 23 invalid copies were subsequently removed so the number of valid questionnaires is 111 . The effective response rate is $23.22 \%$.

\subsection{Research Argument}

In order to achieve the entrepreneurial goal, tangible and intangible assets that play key roles can be used. In response to previous chapters, the vast array of entrepreneurial environment, such as the degree of entrepreneurial management, various financial resources, technology, utilization of labor force, and entrepreneurial counseling activities, can affect entrepreneurial performance.

Fischer \& Reuber (2003) believe that entrepreneurial counseling activities could affect the ideas of entrepreneurs regarding entrepreneurship. O'Connor (2007) holds that from the long-term perspective, entrepreneurial counseling activities are the best assistance available in the entrepreneurial process. In summary, in the entrepreneurial process, entrepreneurial environment can affect entrepreneurial performance. Hence this research will provide the following argument; e.g. If combination of entrepreneurial resources and entrepreneurial counseling are available, entrepreneurial performance will be the sufficiency condition of excellent entrepreneurial performance.

\subsection{Measurement}

In this research framework, the dependent variable is entrepreneurial performance and the interdependent variables are entrepreneurial counseling activities and entrepreneurial environment. The operational definition of the variables and the measurement tools are illustrated as follows:

\subsubsection{Entrepreneur Environment}

Entrepreneur environment in this study refer to the fact that entrepreneurs seek tangible and intangible assets to play key roles to help entrepreneurs achieve goals. Based on the perspective of entrepreneur environment, as proposed by Lichtenstein and Brush (2001) and Dollingers (2003), the measurement tool for entrepreneur environment is adopted in this study. With the help of the empirical experience of entrepreneur counseling activities, 11 items were concluded. A Likert five-point scale is used for measurement as, when the value is higher, its importance is more agreed, and vice versa, with value ranges from 1 point to 5 points. The value of KMO (Kaiser-Meyer-Olkin) in the Entrepreneur Environment Scale is 0.796, and the P value of the Bartlett's spherical test is less than 0.01. After the principal component analysis of EFA (exploratory factor analysis), the value of the characteristics is more than 1 ; three factors are extracted and the accumulated interpreting variable is $72.683 \%$. Orthogonal rotations are then adopted to make sure there is no significant correlation between the factors and that the absolute value of the loads of the factors for each item are more than 0.5 . When the absolute value of the loads of the factors that do not belong to other items are less than 0.4 , constructs can be acquired under the efficiency principle. Consequently, 5 items of factor 1 are relevant to Government Environment, named Government Resources $(\alpha=0.861) ; 4$ items of factor 2 are relevant to Technology Environment, named as Technology Environment $(\alpha=0.826)$; and 2 items of factor 3 are relevant to Knowledge Environment, namely Knowledge Resources $(\alpha=0.843)$.

The overall Cronbach's $\alpha$ is 0.871 , which is in line with the previous perspective of Saunders et al., (1993) who 
stated that the coefficient is over 0.7. Therefore, the results are in the range of high level of reliability, which approves a certain degree of stability and internal consistency.

\subsubsection{Entrepreneur Counseling Activities}

Entrepreneurial counseling activities in this study refer to those entrepreneur counseling activities that could enhance the knowledge and skills of entrepreneurs to reduce risks and uncertainties (James et al., 2012). Based on the perspective of entrepreneurial resources proposed by Nagesh, Narasimha and Murthy (2008), the measurement tool for entrepreneurial resources is adopted in this study. With the help of the empirical experience of entrepreneur counseling activities, 6 items were concluded. A Likert five-point scale was used for measurement as when the value is higher, its importance is more agreed, and vice versa, with values ranging from 1 point to 5 points. The value of KMO (Kaiser-Meyer-Olkin) for the entrepreneurial counseling activities scale is 0.896 , and the $\mathrm{P}$ value of Bartlett's spherical test is less than 0.01. After the principal component analysis of EFA (exploratory factor analysis), the value of the characteristics is more than 1 . One factor is extracted and the accumulated interpreting variable is $72.14 \%$. Orthogonal rotations are then adopted to ensure there is no correlation among the factors and the absolute value of the loads of the factors for each item is more than 0.5. In addition, when the absolute value of the loads of the factors that do not belong to other items is less than 0.4, constructs can be acquired under the efficiency principle. Six items of factor 1 are relevant to the Counseling Activities System ( $\alpha=0.916)$, which is in line with the previous perspective of Saunders et al., (1993) and where the coefficient is over 0.7. Therefore, the results are primarily in the range of high level of reliability, which approves a certain degree of stability and internal consistency.

\section{Research Result}

\subsection{Regression Analysis}

First argument proposed that, in this study the entrepreneurial resources have a significant influence on entrepreneurial performance. As the previous analysis shows, construct factors are extracted to conduct a regression analysis. After regression analysis, the comprehensive adjusted R2 is 0.045 , and the F-Value is 2.729 . In terms of the construct of entrepreneur resources, Government resources, Technology resources, and Knowledge resources have all achieved a significant level. Therefore, first argument is approved to be true. In second argument, in terms of entrepreneurial counseling activities have a significant influence on entrepreneurial performance. After regression analysis, the comprehensively adjusted R2 is 0.039 , and the F-Value is 1.736 . The results are not significant. Therefore, the second argument is proved to be false.

\subsection{Fuzzy Set Qualitative Comparative Analysis}

The program fuzzy-set/qualitative comparative analysis 2.5 (fs/qca.com) is applied to test alternative sufficient conditions propositions of entrepreneurial resources and entrepreneurial counseling activities to entrepreneur performance in the current study. The first step is to calibrate the data collected in the questionnaire survey. This means all variables need to be given values between 0 and 1 . In order to have cases more distinguishable, the analysis includes multiplying the values of all measurements of a variable to make the range of the variable wider, and then proportionally transform those multiplied values into a fuzzy number between 0 and 1 . This study uses a Likert scale range from 1 to 5 , in the questionnaire to measure entrepreneur environment and Entrepreneurial counseling activities to entrepreneurial performance. For example, the multiplying values of the entrepreneurial government resources items in the dataset, the calibration process would then proportionally transform the value 3125 to 1 , and the value 1 to 0 . The "crossover" point between satisfied and unsatisfied patients would be 243 in the middle and coded as 0.5 in the fuzzy set. Other categories in this study are created in parallel fashion. Table 1 exhibits the extreme values and the crossover point of each variable in this study. (see table 1)

Table 1. The extreme values and the crossover points of each condition

\begin{tabular}{ccccccc}
\hline & $\begin{array}{c}\text { Government } \\
\text { resources }\end{array}$ & $\begin{array}{c}\text { Technology } \\
\text { resources }\end{array}$ & $\begin{array}{c}\text { Knowledge } \\
\text { resource }\end{array}$ & $\begin{array}{c}\text { Entrepreneurial } \\
\text { Environment }\end{array}$ & $\begin{array}{c}\text { Counseling } \\
\text { Activities }\end{array}$ & $\begin{array}{c}\text { Calibration of } \\
\text { the value }\end{array}$ \\
\hline Highest value & 3125 & 625 & 25 & 48828125 & 15625 & 1 \\
Crossover point & 243 & 81 & 9 & 177147 & 729 & 0.5 \\
Lowest value & 1 & 1 & 1 & 1 & 1 & 0 \\
\hline
\end{tabular}


If the upper left number is close to 1.0, this indicates sufficiency; in that case, the lower right corner number displays the coverage. Conversely, a number close to 1.0 in the lower right corner indicates a necessary condition; in that case, the upper left number indicates the coverage.

When testing conditions for their necessity, remember that the threshold for consistency should be high (> .9) and its coverage should not be too low (> .5). First argument: When entrepreneurial resources are available, the results (Y) of entrepreneurial performance can be yielded. The findings for consistency (0.938) and coverage (0.834) indicate that the model is useful. (see Figure 1) .

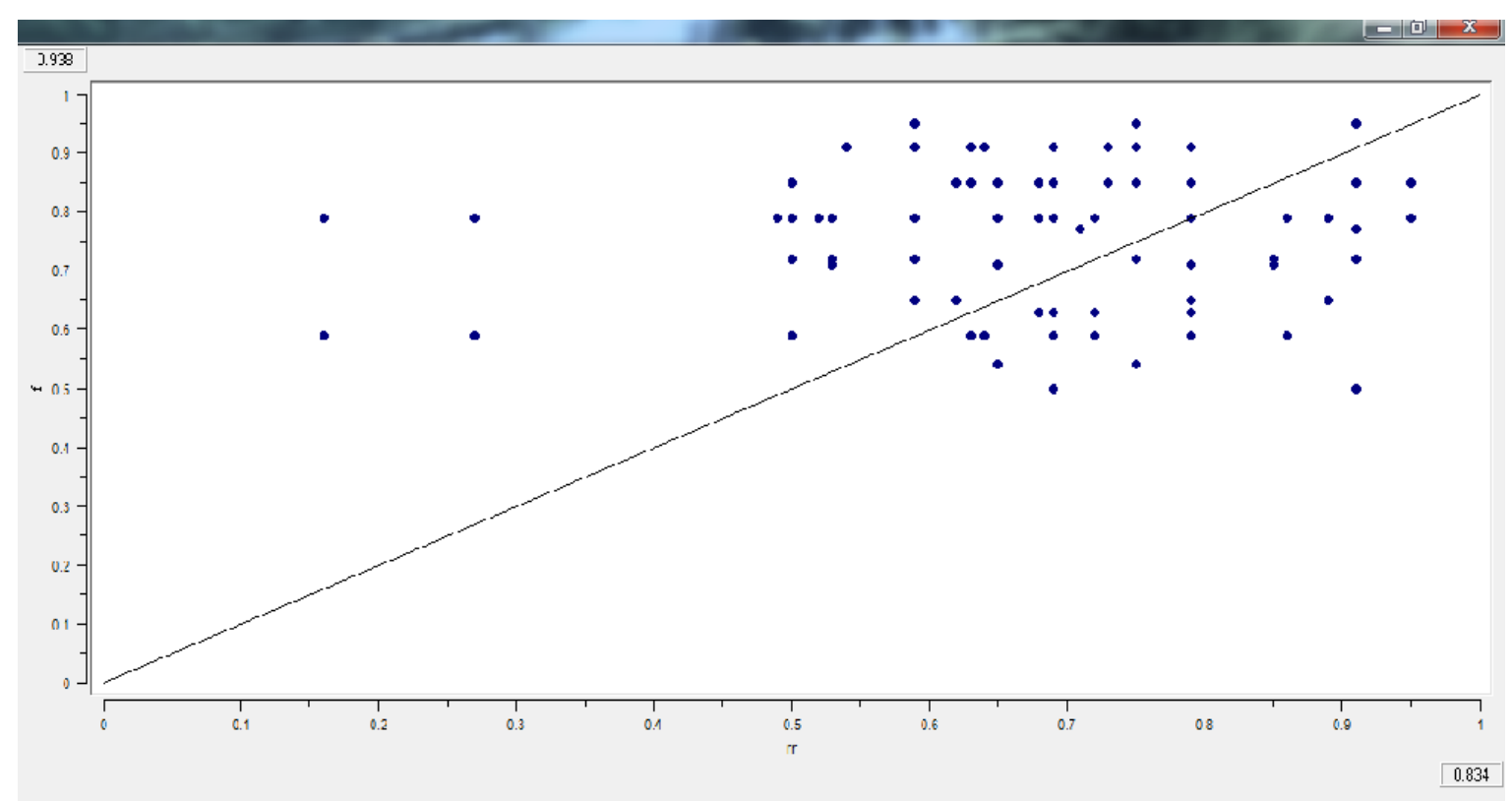

Figure 1. The result of entrepreneurial resources to entrepreneurial performance by fs/QCA

Second argument: When entrepreneurial counseling is available, entrepreneurial performance can be created. The findings for consistency (0.901) and coverage (0.869) indicate that the model is useful and these cases with the outcome are represented by the causal condition. (see Figure 2).

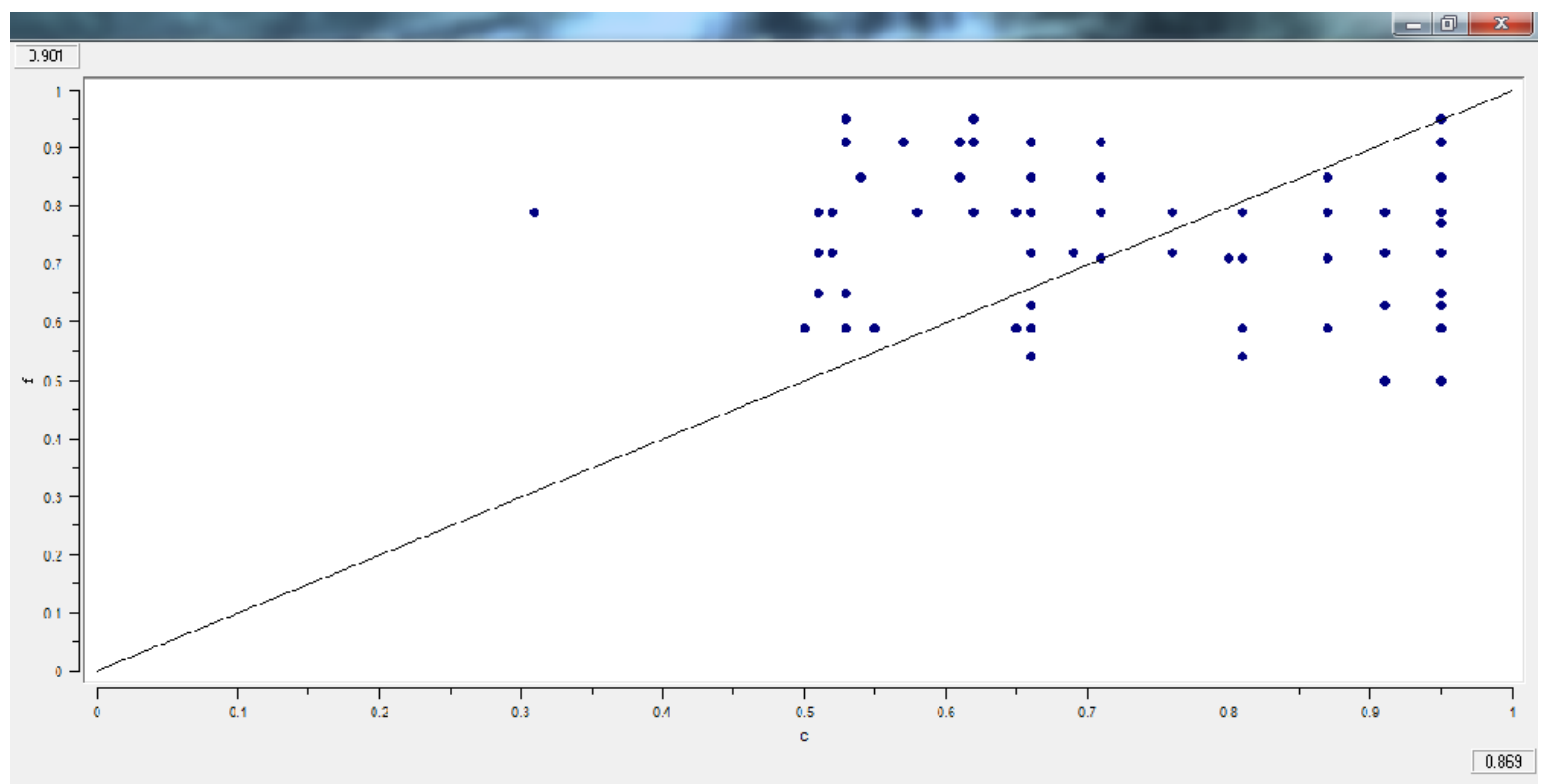

Figure 2. The result of entrepreneurial counseling to entrepreneurial performance by fs/QCA 
We further explored the third argument that demonstrated when a combination of entrepreneurial resources and entrepreneurial counseling are available, entrepreneurial performance will be the sufficiency condition of excellent entrepreneurial performance. The findings for consistency (0.943) and coverage (0.808) indicate that the model is useful. (see Figure3).

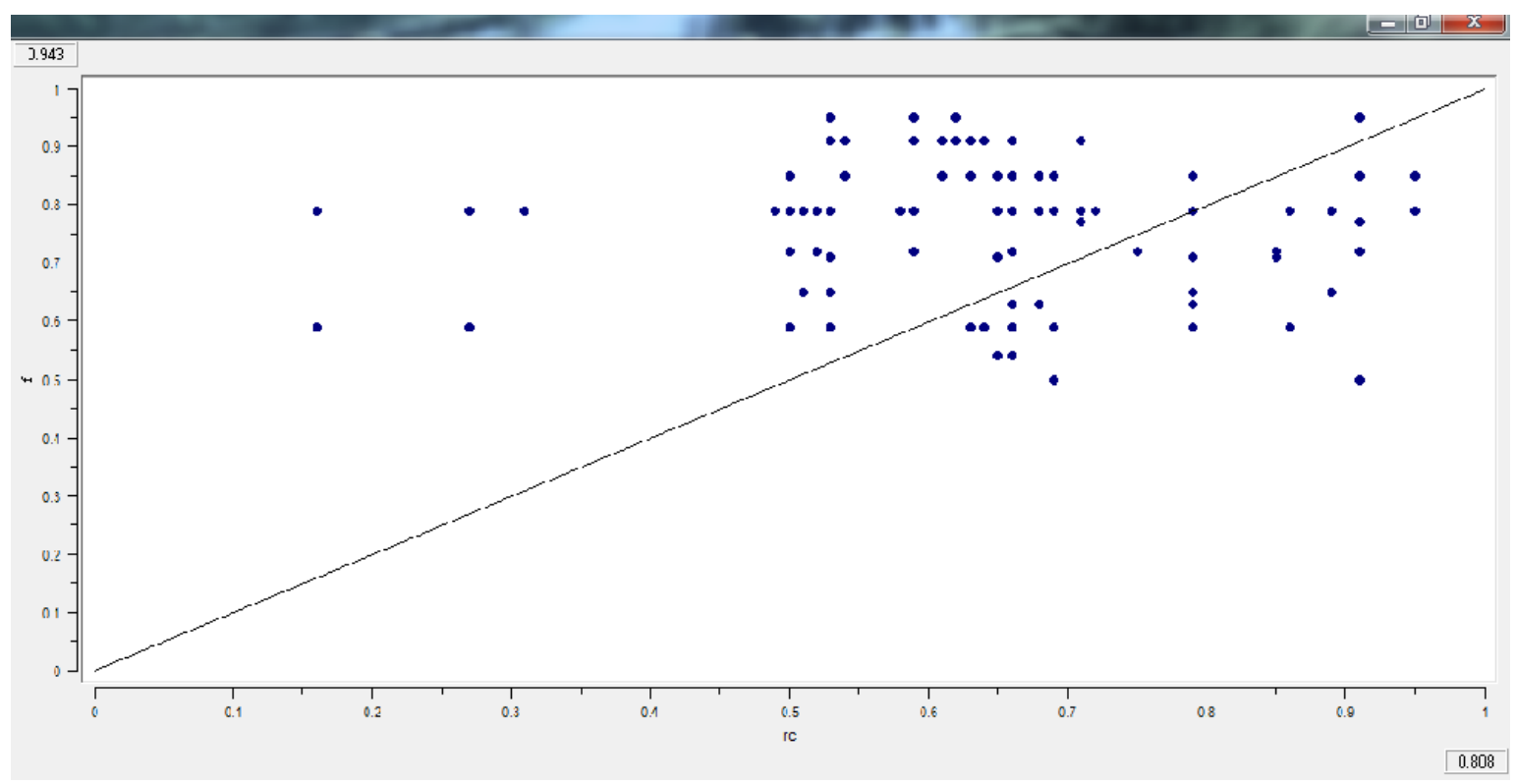

Figure 3. The result of combination of entrepreneurial resources and entrepreneurial counseling to entrepreneurial performance by fs/QCA

Based on the fuzzy set qualitative comparative analysis, the results of $0.834,0.869$ and 0.808 for coverage of the combinations of conditions for the output variable means the causal combination of entrepreneurial environment and counseling activities cover $93.8,90.1$ and 94.3 percent of the entrepreneurial performance. In other words, this also means that 6.2, 9.9 and 5.7 percent of entrepreneurial performance may be caused by other conditions or factors (see table 2).

Table 2. Result of fs/QCA

\begin{tabular}{cccccc}
\hline Argument & Number & Consistency & Coverage & Correlation (High/Low) & Effect Size (High/Low) \\
\hline 1 & 111 & 0.938 & 0.834 & High & High \\
2 & 111 & 0.901 & 0.869 & High & High \\
3 & 111 & 0.943 & 0.808 & High & High \\
\hline
\end{tabular}

\section{Discussions}

In the above study, we adopted regression analysis to testify the significant influence of entrepreneurial environment and entrepreneurial counseling on entrepreneurial performance. The results show that entrepreneurial environment have a significant impact on entrepreneurial performance while there is no significant impact of entrepreneurial counseling on entrepreneurial performance.

In terms of entrepreneur environment, the three factors of government resources, technology resources, and knowledge resources have achieved a significant level, which indicates that entrepreneurial resources have a significant influence on entrepreneur counseling activities. This study is in line with the perspective of Fischer, E., and Reuber, A. R. (2003) who stated that when the degree of emphasis is on the importance of entrepreneurial resources, the degree of recognition for the importance of entrepreneur counseling activities is also relatively higher. Specifically speaking, when an entrepreneur places more emphasis on entrepreneur resources, they will attract more attention to the influence of entrepreneur counseling activities and the establishment of businesses. 
It not only recognizes all possible problems and the gap in entrepreneurial resources in the existing entrepreneurship, but also tries to seek out new methods and solutions with the help of entrepreneur counseling activities to solve the issue of resources. Those individuals with relatively rich entrepreneurial resources will not only have an effective response to the market changes, but also their knowledge of entrepreneurship will also offer the enhancement of products or services, which can be used extensively in the entrepreneur fields.

Through fs/QCA, the results show that there is high causal relevance for entrepreneurial environment, entrepreneurial counseling and the combination of these two on entrepreneurial performance (consistency $\geqslant$ 0.80), indicating that a single factor or the combination of two factors have sufficiency for the results. Specifically, when entrepreneurial resources are available, the results $(\mathrm{Y})$ of entrepreneurial performance are probably yielded. When entrepreneurial counseling is available, the entrepreneurial performance can be created and when the combination of entrepreneurial resources and entrepreneurial counseling is available, entrepreneurial performance can be yielded. However, the entrepreneurial environment or entrepreneurial counseling are not necessarily the only reason for the production of entrepreneurial performance.

Based on the analysis of entrepreneurial plans by researchers on entrepreneurial counseling (Fan, 2013), most entrepreneurs lack enough understanding of the entrepreneurial business model and are over-optimistic for the market. In particular, when technology, products, management, and finance are not professional enough, unsatisfactory entrepreneurial performance will be generated. One-to-one entrepreneurial counseling services with entrepreneurs are conducted to assist with the diagnosis of the business model for a new business and to enhance the insights of entrepreneurs into the market and entrepreneurial skills to enhance the quality and success ratio of entrepreneurs. In the entrepreneurial process, if the resources possessed by entrepreneurs are not enough, the failure ratio of entrepreneurs will be relatively high. Therefore, the results of fs/QCA could support the previous entrepreneurial counseling experience by researchers.

\section{Conclusions}

Vis (2012) point out that "Regression analysis and fs/QCA are built on two different logics. Fs/QCA uses set theory to evaluate necessary or sufficient configurations of conditions that lead to an outcome. Regression analysis statistically evaluates the impact of an independent variable on a dependent variable. Fs/QCA hypotheses test for necessary conditions and sufficient combinations of conditions, the regression hypotheses focus on the average effect of individual variables or interactions." In a regression analysis, such this outcome would amount to a no significant finding. However, a low correlation between variables does not preclude the existence of relationships of necessity and/or sufficiency.

Ragin (2008) also believed that "Since such an fs/QCA analysis still aims to understand how outcomes come about, namely, wants to account for the effect the approach remains more "qualitative" than "quantitative". Fs/QCA and regression differ in how they tackle limited diversity namely, the situation that not all possible combinations of conditions and outcome occur in reality." Therefore, Vis (2012) holds that "This means that a factor that influences the outcome in only a subset of cases - but some cases nonetheless - becomes invisible in a regression analysis; in fact, it only inflates the variance and deflates the coefficients. By formalizing the logic of qualitative analysis, QCA makes it possible to bring the logic and empirical intensity of qualitative approaches to studies that embrace more than a handful of cases research situations that normally call for the use of variable-oriented, quantitative methods."

This study's conclusions have more rich implications, and classification means in reference to future researches. This paper fills the gap from previous studies and the results of this study will be helpful for subsequent scholars to conduct deep researches that exploring sufficiency conditions for entrepreneurial environment and counseling activities on entrepreneurial performance.

\section{References}

Barney, J. B. (1991). Firm resources and sustained competitive advantage. Journal of Management, 17(1), 99-120. http://dx.doi.org/10.1177/014920639101700108

Chang, C. W., Tseng, T. H., \& Woodside, A. G. (2013). Configural algorithms of patient satisfaction, participation in diagnostics, and treatment decisions' influences on hospital loyalty. Journal of Services Marketing, 27(2), 91-103. http://dx.doi.org/10.1108/08876041311309225

Cross, B., \& Travaglione, A. (2003). The untold story: is the entrepreneur of the 21 st century defined by emotional intelligence? International Journal of Organizational Analysis, 11(3), 221-228. http://dx.doi.org/10.1108/eb028973

Dollingers, M. J. (2003). Entrepreneurship: Strategies and Resources (3rd ed.). NJ: Prentice Hall International 
Inc.

Fan, S. C. (2013). Counseling entrepreneurial submissions. Working paper. Council of Labor Affairs, Executive Yuan, Taiwan. http://dx.doi.org/10.1596/1813-9450-6388

Fischer, E. M., Reuber, A. R., \& Dyke, L. S. (1993). A theoretical overview and extension of research on sex, gender, and entrepreneurship. Journal of Business Venturing, 8(2), 151-168. http://dx.doi.org/10.1016/0883-9026(93)90017-Y

Fischer, E., \& Reuber, A. R. (2003). Support for Rapid-Growth Firms: A Comparison of the Views of Founders, Government Policymakers, and Private Sector Resource Providers. Journal of Small Business Management, 41(4), 346-365. http://dx.doi.org/10.1111/1540-627X.00087

Fogel, G. (2001). An analysis of entrepreneurial environment and enterprise development in Hungary. Journal of Small Business Management, 39(1), 103-109. http://dx.doi.org/10.1111/0447-2778.00010

Gourova, E. L. I. S. S. A. V. E. T. A., Todorova, Y. A. N. K. A., \& Gourov, N. I. K. O. L. A. Y. (2009). Skills for future engineers: challenges for universities in Bulgaria'. WSEAS Transactions on Business and Economics, $6(7), 385-399$.

Grant, R. M. (1991). The resource-based theory of competitive advantage: implications for strategy formulation. California Management Review, 33(3), 567-586. http://dx.doi.org/10.2307/41166664

Karunanithy, K., \& Jeyaraman, S. (2013). Impact of Entrepreneurial Characteristics on the Organizational Development of the Small Business Entrepreneurs. Industrial Engineering Letters, 3(6), 28-33.

Kevin, C. W., Thomas, A. T., \& Robert, F. (1999). The Use of Personality and the Five-Factor Model to Predict New Business Ventures: From Outplacement to Start-up. Journal of Vocational Behavior, 54(1), 82-101. http://dx.doi.org/10.1006/jvbe.1998.1654

Kralj, D. A. V. O. R. I. N., \& Markič, M. (2008). Sustainable development strategy and product responsibility. WSEAS Transactions on Environment and Development, 4(2), 109-118.

Lichtenstein, B. M., \& Brush, C. G. (2001). How do "Resource Bundles" Develop and Change in New Ventures? A Dynamic Model and Longitudinal Exploration. Entrepreneurship Theory and Practice, 26(3), 37-58.

Lundström, A., Almerud, M., \& Stevenson, L. (2008). Entrepreneurship and Innovation Policies. Analyzing measures in European countries, FSF 2008: 3.

Mocanu, A. M., Litan, D., Olaru, S., \& Munteanu, A. (2010). Information systems in the knowledge based economy. WSEAS Transactions on Business and Economics, 7(1), 11-21.

Nagesh, P., \& Murthy, M. N. (2008). The Effectiveness of Women Entrepreneurship Training Program: A Case Study. The ICFAI University Journals of Entrepreneurship Development.

O'Connor, S. M. (2007). Teaching IP from an Entrepreneurial Counseling and Transactional Perspective. Louis ULJ, $52,877$.

Ragin, C. C. (2008). Redesigning social inquiry: Fuzzy sets and beyond. Chicago: University of Chicago Press. http://dx.doi.org/10.7208/chicago/9780226702797.001.0001

Saunders, J. B., Aasland, O. G., Babor, T. F., \& Grant, M. (1993). Development of the alcohol use disorders identification test (AUDIT): WHO collaborative project on early detection of persons with harmful alcohol consumption-II. Addiction, 88(6), 791-804. http://dx.doi.org/10.1111/j.1360-0443.1993.tb02093.x

Sharma, D. S., Verma, V., \& Kumar, D. S. (2012). A Review: Women Entrepreneurship “An era of transition”. International Journal in Multidisciplinary and Academic Research (SSIJMAR), 1(3), 1-12.

Srivastava, R. K., Shervani, T. A., \& Fahey, L. (1998). Market-based assets and shareholder value: a framework for analysis. The Journal of Marketing, 2-18. http://dx.doi.org/10.2307/1251799

Taticchi, P., Tonelli, F., Hernandez, E., \& Cagnazzo, L. (2009). Implementation of a Knowledge Management Tool within a VDO Network: Preliminary Results. WSEAS Transactions on Business and E conomics, 6, 2.

Vis, B. (2012). The comparative advantages of fs/QCA and regression analysis for moderately large-N analyses. Sociological Methods \& Research, 41(1), 168-198. http://dx.doi.org/10.1177/0049124112442142

Wang, C. K. (2009). A Study of Entrepreneurship Management in University (Doctoral dissertation).

Woodside, A. G. (2010). Case study research: Theory, methods, practice. Bingley, UK: Emerald Group Publishing. 
Woodside, A. G. (2011), Responding to the severe limitations of cross-sectional surveys: commenting on Rong and Wilkinson's perspectives. Australasian Marketing Journal, 19, $153-6$. http://dx.doi.org/10.1016/j.ausmj.2011.04.004

Woodside, A. G. (2013). How Algorithms with Happiness-at-Work Identify High (Low) Performing Hospitality Frontline-Employees: Transcending Variable and Cases-Based Analyses.

Woodside, A. G., Ko, E., \& Huan, T. C. T. (2012). The new logic in building isomorphic theory of management decision realities. Management Decision, 50(5), 765-777. http://dx.doi.org/10.1108/00251741211227429

Woodside, A. G., Schpektor, A., \& Xia, X. (2013). Triple Sense-Making of Findings from Marketing Experiments Using the Dominant Variable Based-Logic, Case-Based Logic, and Isomorphic Modeling. International Journal of Business and Economics, 12(2), 131-153.

Wu, W. W. (2009). A competency-based model for the success of an entrepreneurial start-up. WSEAS Transactions on Business and Economics, 6(6), 279-291.

Zhao, H., Seibert, S. E., \& Lumpkin, G. T. (2010). The relationship of personality to entrepreneurial intentions and performance: A meta-analytic review. Journal of Management, 36(2), 381-404. http://dx.doi.org/10.1177/0149206309335187

Zhenchang, G. (2003). Youth Unemployment and Employment Prospects. Community Development Journal, 103.

\section{Copyrights}

Copyright for this article is retained by the author(s), with first publication rights granted to the journal.

This is an open-access article distributed under the terms and conditions of the Creative Commons Attribution license (http://creativecommons.org/licenses/by/3.0/). 